\title{
UMA VISÃO CONSTITUCIONAL SOBRE O FENÔMENO SOCIAL DE CHARLOTTESVILLE: A IMPORTÂNCIA DA REGULAMENTAÇÃO DA LIBERDADE DE EXPRESSÃO PELA PENALIZAÇÃO DO "HATE SPEECH"
}

A CONSTITUTIONAL VIEW ON THE SOCIAL PHENOMENON OF CHARLOTTESVILLE: THE IMPORTANCE OF REGULATING FREEDOM OF EXPRESSION BY PENALIZING THE "HATE SPEECH"

Cícero Vogelaar GIRARDI²

Igor Julio MALARDO3

Frederico Thales de Araújo MARTOS ${ }^{4}$

ISSUE DOI: $10.21207 / 2675-0104.2019 .923$

\section{RESUMO}

O presente artigo visa, principalmente, o destaque dos motivos do porquê limitar a liberdade de expressão, ou seja, do porquê a liberdade de expressão deve ser limitada, e não irrestrita, e quais os benefícios disso. Para tanto, utiliza-se o exemplo das manifestações ocorridas em julho de 2017 na

\footnotetext{
${ }^{1} \mathrm{O}$ presente artigo sintetiza a monografia de conclusão da pesquisa, realizada para o Programa Interno de Bolsas de Iniciação Científica (PIBIC 2018-2019) da Faculdade de Direito de Franca (FDF), Franca/SP.

${ }^{2}$ Discente da Faculdade de Direito de Franca (FDF), Franca/SP. Bolsista do Programa Interno de Bolsas de Iniciação Científica (PIBIC 2018-2019).

${ }^{3}$ Discente da Faculdade de Direito de Franca (FDF), Franca/SP. Bolsista do Programa Interno de Bolsas de Iniciação Científica (PIBIC 2018-2019).

${ }^{4}$ Doutor em Direito pela Faculdade Autônoma de Direito - FADISP (2014). Professor Concursado e Titular de Direito Civil na Graduação da Faculdade de Direito de Franca - FDF (2016) e na Universidade do Estado de Minas Gerais, unidade de Frutal - UEMG/Frutal (2018). Advogado inscrito na OAB/SP. Associado ao Conselho Nacional de Pesquisa e Pós-Graduação em Direito CONPEDI e Autor de diversos artigos e livros acadêmicos. Desenvolve pesquisa científica.
} 
cidade americana de Charlottesville, Virginia, manifestações essas de cunho racista, que trouxe à tona toda a questão preconceituosa que assola a sociedade americana e o mundo em geral.

Palavras-chave: Liberdade de expressão. Discurso de ódio. Charlottesville. Impactos jurídicos e sociais.

\section{ABSTRACT}

This article aims primarily at highlighting the reasons why limiting freedom of expression, and why freedom of expression should be limited rather than unrestricted, and what are the benefits of this. To this end, we use the example of the demonstrations that took place in July 2017 in the American city of Charlottesville, Virginia, manifestations of a racist nature, which brought up all the prejudiced issues that plague American society and the world in general.

Keywords: Freedom of speech. Hate speech. Charlottesville. Legal and social impacts.

\section{INTRODUÇÃO}

Consiste em tarefa tortuosa introduzir um tema que, na verdade, devido sua própria natureza, é, por si só, tão abrangente e profundo.

Porém, a presente pesquisa trata basicamente do porquê a liberdade de expressão deve ser restringida nos casos de proliferação do chamado discurso de ódio.

O discurso de ódio nada mais é que aquele discurso que objetiva diminuir, ofender e descaracterizar determinado segmento social por meio de sua ridicularização, disseminando preconceito e ódio.

A presente pesquisa tratou de estudar a imitação da liberdade de expressão apenas nesses casos, não abrangendo essa restrição a outros que nada tenham a ver com o discurso de ódio, defendendo, portanto, a limitação de tão importante dispositivo nos casos do "hate speech".

Para que se conseguisse trazer, mas solidez e concretude à pesquisa, buscou-se um exemplo em que se pudesse observar o discurso de ódio com clareza e porque aquilo deveria ser repudiado a tão grave ponto de ter de restringir a liberdade de expressão.

Esse exemplo foi encontrado nas manifestações ocorridas na cidade de Charlottesville, no ano de 2017, que pregavam ideias rasistas, preconceituosas e nazistas.

Dessa maneira, necessário realizar estudos e reflexões acerca do confrontamento entre a liberdade de expressão e a dignidade da pessoa humana ofendida no discurso já citado.

Dessa maneira, algumas reflexões surgem: Qual dispositivo é mais importante? Existe algum princípio que não tenha limites? A liberdade de expressão deve ser restringida? Se sim, como? 
Mais que isso, importantíssimo é para a compreensão do tema a visualização desta problemática na prática, ou seja, em jurisprudências, e as posições e definições acerca do tema em torno do mundo e no Brasil.

Será estudada a forma que a situação descrita é tratada pela atual legislação brasileira, bem como casos marcantes (caso Elwangger, por exemplo) que trazem à tona o porquê se faz necessário a regulamentação deste assunto, bem como o porquê da disciplinarão penal ser a mais efetiva, nesse caso.

Mais que isso, evidente que, na contemporaneidade, tal fenômeno está cada vez mais se diversificando, além de aumentando, por isso, necessária a análise de como os discursos de ódio e sua consequente penalização vem se mostrando nos dias atuais, sendo intensificados pela internet e principalmente pelas mídias sociais.

Com tudo isso, busca-se mostrar a gravidade tremenda da proliferação do discurso de ódio, gravidade essa tão grande que justificadora à limitação da liberdade de expressão.

\section{DA RESTRIÇÃO DA LIBERDADE DE EXPRESSÃO - CONSIDERAÇÕES INICIAIS}

Evidente que a liberdade de expressão é um dos direitos mais primordiais de um estado democrático de direito, e sua liberdade deve ser garantida e ampla ${ }^{5}$. Na verdade, a liberdade deve ser quase irrestrita, mas

\footnotetext{
${ }^{5}$ Carta de 1988 estabelece expressamente a liberdade em suas diversas acepções, como a liberdade de consciência e de crença, conforme se observa em seus incisos VI e VIII, in verbis: IV - é livre a manifestação do pensamento, sendo vedado o anonimato; (...) VI - é inviolável a liberdade de consciência e de crença, sendo assegurado o livre exercício dos cultos religiosos e garantida, na forma da lei, a proteção aos locais de culto e a suas liturgias; (...) VIII - ninguém será privado de direitos por motivo de crença religiosa ou de convicção filosófica ou política, salvo se as invocar para eximir-se de obrigação legal a todos imposta e recusar-se a cumprir prestação alternativa, fixada em lei. O inciso IX do art. $5^{\circ}$ proíbe a censura, o que é confirmado em seu art. 220 e seus parágrafos, que prevêem, também, a referida vedação, seja de natureza política, ideológica e artística, não admitindo que a manifestação do pensamento, criação, expressão e informação sofra qualquer forma de restrição. Já o art. 220 traz que: A manifestação do pensamento, a criação, a expressão e a informação, sob qualquer forma, processo ou veículo não sofrerão qualquer restrição, observado o disposto nesta Constituição. $\S 1^{\circ}$ Nenhuma lei conterá dispositivo que possa constituir embaraço à plena liberdade de informação jornalística em qualquer veículo de comunicação social, observado o disposto no art. $5^{\circ}, \mathrm{IV}, \mathrm{V}, \mathrm{X}, \mathrm{XIII}$ e XIV. $\S 2^{\circ}$ É vedada toda e qualquer censura de natureza política, ideológica e artística; importante se faz, também, a leitura do art. 244: Não obstante, a liberdade de manifestação do pensamento não pode ser considerada fundamento absoluto, haja vista que deve coadunar-se com todo o ordenamento constitucional, o qual também prevê alguns ônus decorrentes de seu exercício, como a vedação ao anonimato, em seu inciso IV, o direito de resposta e a possibilidade de indenizações em seu inciso V.
} 
não completamente, já que, na visão dessa pesquisa existe pelo menos um fator capaz de limita-lo: O discurso de ódio. Importante se faz ressaltar que a regra é se dar o máximo de liberdade possível a liberdade de expressão, e a exceção é limita-la.

Expressando este entendimento, preconiza o magistério de Comparato (2015, p. 330):

Juridicamente falando, a liberdade é a ausência de proibições ou autorizações prévias, para a prática de atos ou o exercício de alguma atividade profissional. A liberdade de expressão é incompatível com o estabelecimento de censura prévia, de qualquer natureza -política, moral ou religiosa -para os espetáculos públicos ou meios de comunicação de massa. O que não significa que possa ser tolerada uma liberdade irresponsável. Ao contrário, todo abuso deve ser reprimido, pois significa negação ao direito.

$\mathrm{Na}$ sociedade moderna observa-se como situação mais corriqueira o conflito entre o direito à liberdade de expressão e o princípio da dignidade da pessoa humana, ou seja, é muito comum na sociedade contemporânea que uma opinião, uma ideologia ou um modo de pensar firam subjetivamente a dignidade de uma ou uma classe de pessoas.

Esse fenômeno ainda foi potencializado pela internet, visto que esta ferramenta possibilita a difusão massiva e intensificada de ideias a todo momento e das mais variadas formas. Ou seja, a internet, e o consequente desenvolvimento das redes sociais potencializaram a difusão dos modos de pensar, inclusive daqueles racistas, preconceituosos ou que de alguma forma, possam de alguma forma ferir a dignidade humana. Dessa maneira, também foi potencializado o conflito entre a propagação dessas ideias e o sentimento de dignidade afetado por algumas pessoas.

Mas que isso, evidente que se trata de tarefa dificílima definir qual o princípio mais importante: liberdade de expressão ou a dignidade da pessoa humana. É, então impraticável a aplicável o princípio de interpretação constitucional da proporcionalidade, uma vez que é quase impossível definir a importância maior de dois direitos tão fundamentais em nosso ordenamento. Faça necessário então a aplicação do princípio da harmonia, devendo-se sempre tentar harmonização máxima dos tais direitos citados. 


\subsection{O CONCEITO DE DISCURSO DE ÓDIO OU "HATE SPEECH"}

O conceito de discurso de ódio e de extrema importância, uma vez que, na visão dessa pesquisa é o principal fator limitador da liberdade de expressão. Ora, uma vez constatada que a liberdade de expressão deve sofrer periódicas limitações, e que o discurso de ódio é a principal delas, o "hate speech" se transforma na principal figura jurídica capaz de frear uma opinião preconceituosa disfarçada de opinião.

E de muita dificuldade a delimitação do discurso de ódio por se tratar de conceito tão amplo e também subjetivo, conceito também, que envolve uma pluralidade de aspectos.

Nesse sentido, Gilmar Mendes:

O tema é, sem dúvida, um tanto paradigmático, pois nos leva a questionar a respeito dos próprios limites da liberdade de expressão, nos obriga a refletir sobre a necessidade de se diferenciar a tolerância do dissenso e a examinar a impossibilidade de se tolerar a intolerância, em vista de seu potencial disseminador do ódio em sociedades democráticas 6

Outro desafio, é a examinação de se a intolerância deveria ser tolerada em nome da própria tolerância, mas este paradigma será tratado em tópico a parte desta mesma pesquisa. Por mais delituosa que possa ser a caminhada no sentido de delimitar as situações envolvidas no discurso de ódio, e necessário e preciso estabelecer-se um conceito prático para este fenômeno. Para André de Carvalho Ramos, "o discurso do ódio (hate speech) consiste na manifestação de valores discriminatórios, que ferem a igualdade, ou de incitamento à discriminação, violência ou a outros atos de violação de direitos de outrem ${ }^{7}$

Silva (2011, p. 447) apresenta a seguinte definição:

O discurso de ódio compõe-se de dois elementos básicos: discriminação e externalidade. É uma manifestação segregacionista, baseada na dicotomia superior (emissor) e inferior (atingido) e, como manifestação que é, passa a existir quando é dada a conhecer por outrem que não o próprio autor. A fim de formar um conceito satisfatório, devem ser aprofundados esses dois aspectos, começando pela externalidade. A existência do discurso de ódio, assim toda expressão discursiva, exige a transposição de ideias do plano mental (abstrato) para o plano fático (concreto).

\footnotetext{
${ }^{6}$ MENDES, Gilmar Ferreira. "A jurisdição constitucional no Brasil e seu significado para a liberdade e a igualdade". Disponível em: Acesso em: 24 fev. 2019

${ }^{7}$ RAMOS, André de Carvalho. Curso de Direitos Humanos. 2. ed. rev. atual. ampl. São Paulo: Saraiva, 2015 , p. 524.
} 
Discurso não externado é pensamento, emoção, o ódio sem o discurso; e não causa dano algum a quem porventura possa ser seu alvo, já que a ideia permanece na mente de seu autor. Para esse caso, é inconcebível a intervenção jurídica, pois a todos é livre o pensar.

Dessa maneira, o discurso de ódio ou o "hate speech" é aquele discurso que tem por finalidade incutir o ódio, o preconceito o a intolerância, contra determinados grupos sociais. É o discurso discriminatório capaz de desbalancear a igualdade entre as pessoas, atribuindo a elas características ofensivas a sua dignidade.

\subsection{A INTERNET COMO MEIO PROPAGADOR}

Antes de entender porque a internet auxiliou o processo de difusão de ideias preconceituosas, faz-se necessário o estabelecimento de um conceito que ajude a entender tal tecnologia.

De acordo com Blum, Bruno e Abrusio ${ }^{8}$

[...] ela é uma imensa Rede, ou seja, Rede das Redes, vista como um meio de comunicação que interliga dezenas de milhões de computadores no mundo inteiro [...] anulando toda distância de lugar e tempo, através de diversas funções, podendo citar, dentre elas, e-mail (correio eletrônico), ecommerce (comercio eletrônico), e-government (governo eletrônico), elearning (ensino a distância) entre outras. Atualmente não pertence a nenhum país, podendo ser utilizada por todos.

Assim, a qualquer instante qualquer tipo de opinião, seja ela brilhante, ou seja, ela preconceituosa, pode ser emitida, compartilhada e apoiada. Dessa maneira, a internet proporcionou a divulgação e propagação em massa de ideais, sendo emissor qualquer pessoa com acesso à internet e o receptor uma mesma pessoa com este mesmo acesso. Conforme estabeleceu o filósofo italiano Umberto Eco "As redes sociais deram o direito à palavra a uma legião de imbecis" ${ }^{\text {" }}$. Dessa maneira, indivíduos com

\footnotetext{
${ }^{8}$ (ABRUSIO, P.26);

${ }^{9}$ ECO, Umberto, Redes sociais deram voz a uma legião de imbecis. Declaração dada em um evento em que recebeu o título de doutor honoris causa em comunicação e cultura na Universidade de Turim, norte da Itália, 2015. Disponível em:<https://noticias.uol.com.br/ultimas-
} 
pensamentos fossilizados e odiosos conseguem, através da internet se conhecerem por meio de sua identidade de ideias e juntos podem começar a propagá-las e defendê-las.

Uma vez disseminado o discurso de ódio pela internet, este fatalmente encontrara adeptos de sua corrente discriminatória, que, encobertados pela segurança da distância proporcionada pela internet, passarão a ser adeptos dessas ideias odiosas e propaga-las de maneira ainda mais massiva.

É um exemplo desses debates, a seguinte assertiva de Leandro Karnal:

Hoje é um clique e um site, com muitas imagens. Facilitamos muito para quem odeia. O ódio tem imenso poder retórico. Ele sempre existiu. Agora, existe este ódio prêt-à-porter, pronto, onde você se serve à la carte e pega seu prato preferido. ${ }^{10}$

\subsection{PRINCÍPIO DA TOLERÂNCIA DE KARL POPPER}

Como já citado anteriormente os maiores desafios de se delimitar o discurso de ódio e a sua confrontação com a liberdade de expressão não é conceitual ou jurídico, ou ainda de caráter dogmático, mas sim, filosófico.

Logo surge uma aparente contradição: ao não se respeitar uma ideia odiosa e preconceituosa propagada por um indivíduo, não se estaria também praticando uma intolerância com aquele que proferiu a ideia odiosa?

Tal pensamento faria sentido com a consideração de que um pensamento intolerante e de ódio fosse uma mera opinião técnica ou lógica, se fosse assim, tratar-se-ia de uma opinião. Porém, uma vez que um indivíduo arraiga em seu discurso ideais com caráter explicitamente discriminatório e ofensivo para desqualificar alguém em sua condição de ser humano, evidente que tal pensamento não pode ser tratado como uma mera opinião, mas sim de um pensamento meticuloso previamente articulado com a intenção de diminuir, não apenas de refletir filosoficamente uma situação contemporânea.

noticias/ansa/2015/06/11/redes-sociais-deram-voz-a-legiao-de-imbecis-diz-umberto-eco.jhtm>. Acesso em 30 de março de 2019.

${ }^{10}$ KARNAL, Leandro. Entrevista concedida a BBC, 2017. Disponível em: <https://www.bbc.com/portuguese/brasil-38751447>. Acesso em: 12 abril de 2019 
Dessa maneira, considerando-se de que adotar este método seria desestimular a promoção de uma sociedade mais justa e igualitária, tolerar os intolerantes seria, na verdade, a própria negação da tolerância. Citando Karl Popper: "Se estendermos a tolerância ilimitada mesmo àqueles que são intolerantes, se não nos encontramos preparados para defender uma sociedade tolerante contra as arbitrariedades dos intolerantes, o resultado será a destruição dos tolerantes e, com eles, da tolerância. ", ou seja, é preciso condenar a intolerância e não apenas ignora-la, pois, desconsiderar a intolerância seria a própria negação da tolerância.

\section{FENÔMENO SOCIAL DE CHARLOTTESVILLE}

Dessa maneira, a análise e a explicação das manifestações ocorridas na citada cidade norte-americana, torna-se fundamental para a presente pesquisa no sentido de embasar a teoria, assim, trazendo à realidade um modo como o assunto abordado nessa pesquisa se insere na realidade, produzindo resultados nesta.

\subsection{DELIMITAÇÕES E CAUSAS DO ACONTECIMENTO}

O evento de Charlottesville nada mais do que é um conjunto de manifestações referente a indignação por parte da sociedade devido a um projeto impetrado pelo prefeito da cidade de Charlottesville que tinha como objetivo a retirada de um monumento histórico que se encontrava na cidade, enaltecendo o general confederado Robert E. Lee, que foi um oficial militar de carreira norte-americano conhecido por ter comandado o Exército da Virgínia do Norte durante a Guerra Civil Americana, e tido como um símbolo histórico do Sul dos Estados Unidos.

Esta manifestação, mais conhecida como "Unir a Direita" ("Unite the Right") contou com a presença de neo-confederados, neonazistas e uma grande frota armada, portando tochas, símbolos nazistas, símbolos dos exércitos confederados reivindicando para que o monumento do general não fosse retirado, e isso acabou ocasionado uma das manifestações contemporâneas mais influentes por todo o mundo, por ter como marco principal a volta da Ku Klux Klan, um grupo de supremacistas 
brancos que estão ligados diretamente com o racismo contra afroamericanos cujos foram perseguidos veemente na década de 1920.

O desfecho principal, foi a dura crítica que o prefeito da cidade de Charlottesville prolatou sobre as manifestações de extrema-direita, e aos olhos do prefeito essas manifestações foram "cenas lamentáveis de ódio e covardia das pessoas". Porém, de outro lado, o presidente dos Estados Unidos, Donald Trump, acabou por condenar ambas as manifestações como cenas de ódio.

Este tipo de fenômeno é caracterizado principalmente pela generalização. Por um lado, a generalização, até certo ponto, é inerente à natureza humana uma vez que busca compreender o universo em que vivemos de uma maneira mais ampla, buscando conceitos que definam a humanidade e um modo de se ver o mundo. O problema é aplicação da generalização de maneira indiscriminada, sem buscar entender as diferenças entre cada grupo social e também as possíveis diferenças individuais que toda pessoa possui.

\subsection{DISCURSO DE ÓDIO NESTE EVENTO}

Neste evento em especifico o discurso de ódio consistiu no chamado discurso supremacistas-branco, que se trata basicamente daquele discurso que exalta os indivíduos brancos como superiores àqueles que são de outra etnia.

Assim, a reunião desses manifestantes teve por objetivo enaltecer sua própria suposta superioridade em relação àqueles que não possuem sua mesma característica.

Até por isto, este discurso de ódio contou com a elucidação de símbolos nazistas, já que possui similaridade com o discurso à época da Alemanha-nazista, que enaltecia a raça ariana como superior as demais, pregando a "purificação" da raça, enaltecendo as qualidades próprias de sua raça e diminuindo os "impuros" como ciganos, gays, negros e judeus. Nesse sentido, observada uma certa similaridade entre esses dois discursos quanto ao seu conteúdo, mudando o objeto do ódio.

Todo esse discurso foi embasado na negação da retirada do monumento histórico do general Robert E. Lee, por se tratar de um símbolo da resistência da abolição da escravatura nos Estados Unidos da América e o consequente empoderamento da "raça branca". Ora, a retirada do monumento em questão pelo Estado, significaria a não compactuação do 
governo norte-americano com as ideias defendidas pela pessoa representada pelo monumento em questão, e assim a consequente repudia institucional do governo aos preceitos ali representados, se tornando então de interesse daqueles que continuam a pensar dessa maneira, a manutenção da estátua no lugar em que se encontra, com o objetivo de uma espécie de naturalização das ideias intrínsecas a aquele símbolo.

Tal acontecimento foi aproveitado pela chamada Ku Klux Klan para voltar aos holofotes. Conceitua Daniel Neves Silva:

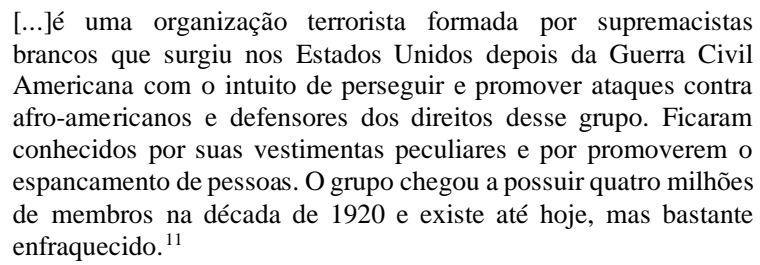

\subsection{CONSEQUÊNCIAS JURÍDICAS E SOCIAIS}

Este caso repercutiu juridicamente, quando o governador de Charlottesville decretou estado de emergência pois estas tomaram proporções alarmantes para a sociedade e o bom convívio social e a polícia tomou a iniciativa de proibir temporariamente manifestações decorrentes das já ocorridas até que a situação se normalizasse.

A imprensa mundial repercutiu o caso repudiando em sua maioria o caráter das manifestações originais, mostrando o conflito violento entre os grupos e relatando os ocorridos durante a manifestação.

\section{DA NÃO PENALIZAÇÃO}

Alguns entendem, que na verdade, a não penalização do "hate speech" é a melhor alternativa quanto ao tema abordado, segundo este raciocínio a liberdade de expressão séria irrestrita, ou, em outro modo de dizer, não teria limites.

11 SILVA, Daniel Neves. "Ku Klux Klan"; Brasil Escola. Disponível em: https://brasilescola.uol.com.br/historiag/ku-klux-klan.htm. Acesso em 08 de junho de 2019. 
Essa teoria é embasada no princípio de que qualquer tipo de limitação a liberdade de expressão consistiria na verdade em uma espécie de censura, segundo esta teoria a liberdade de expressão quanto restrita não seria, na verdade uma verdadeira liberdade de expressão, porque condicionada a uma vontade legislativa, ou seja, à vontade do legislador.

Ora, evidente que nenhuma norma penal é dotada de uma vontade por trás de um legislador que a elabora, nesse sentido qualquer atividade que visasse a limitação da liberdade de expressão estaria condicionada a princípios que não necessariamente correspondem à visão da coletividade como um todo, mas somente daquilo socialmente tolerável.

Os defensores dessa tese, portanto, defendem o ideal de que nunca se poderá adotar um critério absolutamente suficiente para restringir tão importante preceito de uma sociedade moderna, ou seja, a limitação à liberdade de expressão nunca seria suficientemente perfeita ao ponto de fazê-lo sem causar prejuízos a essa liberdade. Em outras palavras: a tipificação de limitações a liberdade de expressão sempre acarretaria de alguma maneira em prejuízo, em algum ponto, a o exercício regular da liberdade de expressão.

Profundo defensor das liberdades, John Stuart Mill, filósofo e economista inglês do século XIX, via na expressão o veículo pelo qual o indivíduo poderia de fortalecer e as sociedades avançar. De acordo com ele, a insistência de um debate livre e aberto é um obstáculo ao desenvolvimento tanto do indivíduo, quanto da sociedade. Em suas palavras:

Nossa intolerância meramente social não mata ninguém, não acaba com opiniões, mas induz os homens a disfarçá-las, ou a abster-se de qualquer esforço ativo para sua difusão. Com a gente, as opiniões heréticas não ganham perceptivelmente, ou mesmo perdem, espaço a cada década ou geração; elas nunca vislumbram o longe, mas continuam a arder nos círculos estreitos de pensamento e de pessoas estudiosas, entre as quais se originam, sem iluminação, os assuntos gerais da humanidade ou com uma verdade ou uma luz enganosa. E assim é mantido um estado de coisas muito satisfatório para algumas mentes, pois, sem o desagradável processo de multar ou de prender ninguém, ele mantém todas as opiniões aparentemente predominantes imperturbável, enquanto não faz absolutamente interdito o exercício da razão por dissidentes aflitos com a doença do pensamento. (...), mas o preço pago por esse tipo de pacificação 
intelectual, é o sacrifício de toda a coragem moral da mente humana. $^{12}$

Os Estados Unidos da América, salvaguardam o direito à liberdade de expressão por meio da primeira emenda da constituição dos Estados Unidos da América:

O congresso não deverá fazer qualquer lei a respeito de um estabelecimento de religião, ou proibir o seu livre exercício; ou restringindo a liberdade de expressão, ou da imprensa; ou o direito das pessoas de se reunirem pacificamente, e de fazerem pedidos ao governo para que sejam feitas reparações de queixas. ${ }^{13}$

Dessa maneira, pode-se observar que a constituição dos EUA protege até mesmo aquele discurso mais ofensivo e preconceituoso, sendo esta proteção estendida até o próprio Estado, uma vez que, estabelece-se que não se fará nenhuma lei que possa restringir a liberdade de expressão.

Como dito anteriormente, isto ocorre porque assume-se que o sistema americano é construído com base no livre intercâmbio de ideias, daí advindo o termo "livre mercado de ideias", que contribuiria e encorajaria uma maior compreensão e busca pela verdade. Dessa maneira acredita-se que a melhor maneira de se buscar o discurso ideal não seria por meio da repressão, mas por meio de mais discursos, contraponto aquele discurso considerado extensivo.

Mesmo o livre mercado de ideias não é absoluto, contando com exceções rigorosamente definidas, que mesmo com a ampla proteção da primeira emenda impõe restrições envolvendo em sua maioria a neutralidade do conteúdo. Contendo também raras restrições quanto ao conteúdo.

As restrições de conteúdo neutro são estabelecidas de maneira geral pelo governo, contendo restrições ao tempo, lugar e modo do exercício da liberdade de expressão que não sejam baseadas no conteúdo do discurso. Essas restrições, portanto, devem ter: conteúdo neutro, servir ao interesse do governo e deixar em aberto outros canais de comunicação. ${ }^{14}$

Um exemplo deste tipo de restrição pelo governo norteamericano é a fixação do volume de altos falantes usados em um distrito comercial.

\footnotetext{
${ }^{12}$ MILL, John Stuart. On liberty. New York: Dover Publications Inc., 2002, p. 27

${ }^{13}$ ESTADOS UNIDOS DA AMÉRICA. Primeira Emenda à Constituição dos Estados Unidos de 15 de dezembro de 1791

${ }^{14}$ Perry educ. Ass'n v. Perry Educators'Ass'n, 460 U.S.37, 45 (1983)
} 
Porém, existem restrições com base no conteúdo, sendo essas extremamente raras. As restrições em questão podem ser conciliadas com o abrigo dado a primeira emenda a liberdade de expressão. As limitações a liberdade junto ao conteúdo são as seguintes: incitação à violência iminente, ameaças reais, difamação e obscenidade.

Uma consequência jurídica pode ser expressa por casos concretos. Por exemplo, em 1969 um membro da Ku Klux Klan fez um discurso em que defendia uma vingança contra judeus e afro-americanos. Porém, a corte americana derrubou uma lei que proibia este discurso porque entenderam, que na verdade, esta lei criminalizava um discurso que não tinha a intenção de incitar ou produzir ação ilegal e iminente e que não era provável que incitasse ou produzisse tal ação. ${ }^{15}$

Em grosso modo, surge um conflito entre as questões filosóficas de ambas as teorias: a liberdade de expressão como sendo uma verdadeira liberdade apenas quando irrestrita versus a liberdade restrita ao mínimo possível em detrimento do princípio da dignidade da pessoa humana.

Tal confronto será melhor explicado e discutido no decorrer desta pesquisa, mas cumpre enfatizar que o princípio da dignidade da pessoa humana é aquele que deve ser norteador de toda a sociedade moderna, juntamente com a liberdade. Por isso, tão difícil se faz conciliar tal situação em que estes dois princípios se colidem, surgindo a questão: até que ponto a liberdade é liberdade e qual o limite da dignidade quando confrontada com autonomia individual?

\section{DA PENALIZAÇÃO}

Como já dito anteriormente, a liberdade de expressão pode ou não ser absoluta, tendo cada modelo seus prós e contras. Porém, na visão destes pesquisadores a penalização é a melhor maneira de se tratar o discurso de ódio ou o "hate speech" e assim, consequentemente, limitar a liberdade de expressão.

Ocorre que a penalização carrega consigo uma experiência histórica de situações fáticas caóticas influenciadas e solidificadas por discursos embasados no discurso de ódio, tornando-se necessária esta

\footnotetext{
${ }^{15}$ Broundenburg v. Ohio, 395 U.S. 444, 446 (1969)
} 


\section{tipificação penal para que o Estado não se omita no dever de prevenção de eventuais situações catastróficas. \\ Ensina Bobbio (2014, p. 162):}

A sanção afirma-se, não é elemento constitutivo do direito, porque um ordenamento jurídico conta, antes de tudo, com a adesão espontânea às suas regras, isto é, com a obediência não por temor das consequências desagradáveis de uma eventual violação, mas por consenso ou convenção, ou mero hábito, de qualquer forma, por motivos que não pressupõem a possível movimentação do mecanismo da sanção. O que seria de nós, observa-se, caso um ordenamento jurídico não pudesse contar de algum modo com o consenso de seus membros? Como poderia ser eficaz, se a eficácia devesse ser obtida somente com a força? Tese semelhante se apoia na constatação de que, na maioria dos casos, a ação dos cidadãos é conforme as regras de conduta estabelecidas pelo ordenamento jurídico, e que os casos de violação não são a regra, mas a exceção

\section{$5.1 \quad$ LEI $7.716 / 89$}

legislativa:

\section{É uma decisão que reflete a importância desta complementação}

HABEAS CORPUS SUBSTITUTIVO DE RECURSO

PRÓPRIO. IMPOSSIBILIDADE. ART. 2, § 2º, LEI N. 7.716/89. DISCRIMINAÇÃO RELIGIOSA. RACISMO. VIOLAÇÃO AO PRINCÍPIO DA CORRELAÇÃO. INOCORRÊNCIA. ATIPICIDADE DA CONDUTA. AUSÊNCIA DE DOLO DE DISCRIMINAÇÃO. REVISÃO DE CONTEXTO FÁTICOPROBATÓRIO. IMPOSSIBILIDADE. EXERCÍCIO DOS DIREITOS DE LIBERDADE DE CULTO E DE RELIGIÃO. LIMITES EXCEDIDOS. SUBSUNÇÃO DA CONDUTA AO TIPO PENAL EM COMENTO. CASO QUE DIVERGE DO PRECEDENTE INVOCADO. HABEAS CORPUS NÃO CONHECIDO. 1. Diante da hipótese de habeas corpus substitutivo de recurso próprio, a impetração sequer deveria ser conhecida, segundo orientação jurisprudencial do Supremo Tribunal Federal e do próprio Superior Tribunal de Justiça. Contudo, considerando as alegações expostas na inicial, razoável a análise do feito para verificar a existência de eventual constrangimento ilegal que justifique a concessão da ordem de ofício. 2. O princípio da congruência, em processo penal, reside na relação entre os fatos imputados na denúncia e os motivos do provimento do pedido de condenação. As instâncias ordinárias após a exauriente análise dos elementos probatórios, chegaram a conclusão de que o fato imputado ao paciente se subsumiu, perfeitamente, ao tipo penal em comento. Assim, não há que se falar em falta de congruência entre denúncia e o decisium, quando os fatos imputados ao paciente 
foram os mesmos que justificaram o édito condenatório. 3. As premissas firmadas pelas instâncias ordinárias dão conta de que não se trata apenas de defesa da própria religião, culto, crença ou ideologia, mas, sim, de um ataque ao culto alheio, que põe em risco a liberdade religiosa daqueles que professam fé diferente a do paciente. $\mathrm{O}$ acórdão impugnado expressamente considerou que o paciente pregava "o fim das Igrejas Assembleia de Deus e igualmente pratica a intolerância religiosa contra judeus". 4. Pela simples leitura da sentença condenatória, percebe-se que as condutas atribuídas ao paciente e ao corréu eram direcionadas contra várias religiões (católica, judaica, espírita, satânica, wicca, islâmica, umbandista e, até mesmo, contra outras denominações da religião evangélica), pregando, inclusive o fim de algumas delas e imputando fatos criminosos e ofensivos aos seus devotos e sacerdotes, como assassinato, homossexualismo, prostituição, roubo, furto, manipulação, et cetera. 5. Maiores incursões no sentido de aferir se as palavras proferidas pelo réu, em textos e em vídeos, publicados na internet, possuíam ou não caráter discriminatório, bem como o dolo de incitar a discriminação religiosa, demandaria a aprofundada incursão probatória, providência incompatível com os estreitos limites do habeas corpus. Habeas corpus não conhecido. ${ }^{16}$

\subsection{PRINCÍPIO DA DIGNIDADE DA PESSOA HUMANA}

A dignidade humana é o valor soberano com a premissa de tornar a sociedade justa, igualitária e solidária, é o princípio basilar a partir do qual decorrem todos os demais direitos fundamentais - norma fundante, orientadora e condicional, não só para a criação, interpretação e aplicação, mas para a própria existência do direito e da harmonização social que norteiam também os costumes.

E se encontra na Constituição Federal de 1988, no título "Dos Princípios Fundamenteis", em seu artigo $1^{\circ}$, III, dispõe in verbis:

Art. $1^{\circ}$ - A República Federativa do Brasil, formada pela união indissolúvel dos Estados e Municípios e do Distrito Federal, constitui-se em Estado Democrático de Direito e tem como fundamento $[\ldots]$ III - a dignidade da pessoa humana.

\section{No dizer de Celso Antônio Bandeira de Mello:}

Princípio é, pois, por definição, mandamento nuclear de um sistema, verdadeiro alicerce dele, disposição fundamental que se

${ }^{16}$ (STJ - HC: 388051 RJ 2017/0028552-0, Relator: Ministro JOEL ILAN PACIORNIK, Data de Julgamento: 25/04/2017, T5 - QUINTA TURMA, Data de Publicação: DJe 04/05/2017) 


\begin{abstract}
irradia sobre diferentes normas, compondo-lhes o espírito e servindo de critério para sua exata compreensão e inteligência, exatamente por definir a lógica e a racionalidade do sistema normativo, no que lhe confere a tônica e lhe dá sentido harmônico. $^{17}$
\end{abstract}

Este princípio é aquele fundamental para nortear de forma coesa todos os outros princípios que compõem o nosso ordenamento jurídico e social, funciona como um catalisador, uma espécie de afunilamento de todas os aspectos que rodeiam e estão veemente entranhados em nosso cotidiano e, na visão dos pesquisadores, de extrema importância de existir uma correlação entre a penalização do discurso de ódio e este princípio.

\title{
5.3 CASO ELLWANGER - HABEAS CORPUS № 82.424
}

Siegfried Ellwanger Castan foi um industrial, escritor e livreiro brasileiro e fundador da Editora Revisão, onde publicava seus livros que distorciam a história do genocídio dos judeus através da afirmativa de que não foi real e negador veemente do Holocausto, e por tais negações, seus livros foram considerados antissemitas.

Na obra mais famosa - e quiçá mais polemica - Acabou o gás! ... $O$ fim de um mito, o escritor através de diversos estudos em documentos históricos da Segunda Guerra Mundial argumento em seu livro sobre a não existência e da impossibilidade de haver camarás de gás nos campos de concentração e que não eram campos feitos para eliminar os judeus, mas sim, um centro de trabalho forçado e que o genocídio judeu não passou de uma farsa, uma mentira forjada para manchar a história alemã e em seu outro título Holocausto: judeu ou alemão? Ellwanger argumenta que o holocausto não passou de um mito para impedir a Alemanha de Hitler continuar se erguendo e aumento seu poder tanto político como econômico.

$\mathrm{Na}$ data de 14 de novembro de 1991 foi recebida a denúncia contra Siegfried Ellwanger na $8^{a}$ Vara Criminal da Comarca de Porto Alegre, onde em primeiro grau fora absolvido. Castan foi, então, em 1995, julgado e absolvido em primeira instância; contudo, em 1996 foi condenado por unanimidade pelos desembargadores da $3^{\text {a }}$ Câmara Criminal do Tribunal de Justiça do Estado do Rio Grande do Sul.

${ }^{17}$ BANDEIRA DE MELO, Celso Antônio. Curso de Direito Administrativo. 10 a ed. São Paulo: Malheiros 1998, pág. 583-584 
Após entraves naquela instancia extraordinária, em 17 de setembro de 2003, finalmente foi julgado o Habeas Corpus que sob $\mathrm{n}^{\circ}$ 82.424, e com isso colocando termo a uma batalha incansável que culminou em manter a condenação do TJRS em desfavor de Ellwanger.

\section{CONSIDERAÇÕES FINAIS}

Consiste em tarefa complicadíssima elaborar considerações finais e certezas cerca de um tema com tantas divagações filosóficas e subjetividades. Contudo, necessário se faz que seja elaborada uma retomada, e assim, algumas ponderações pertinentes com a devida conclusão da pesquisa.

Restou evidente a carga (tanto extensa quanto importante), do debate filosófico como um influenciador nesse tema. Ora, a concordância ou não com a presente tese contida nessa pesquisa será acolhida ou não também pelo modo de ver o mundo de cada indivíduo.

O modo que a presente dupla resolveu abordar e pensar esta tese, em seu sentido filosófico, foi a da liberdade atrelada à responsabilidade. Essa correlação se dá no sentido que liberdade e responsabilidade são indissociáveis, ou melhor: uma não existe sem a outra.

A pergunta que se faz é: a liberdade quando irrestrita configurase na verdade naquela que levará a humanidade a um melhor convívio e harmonia? Ou é uma liberdade egoísta que busca se desprovir de responsabilidade, enquanto atinge objetivos pessoais?

Daí surgiu o posicionamento da presente dupla de pesquisadores de apoiar o ideal de que a liberdade de expressão também deva apresentar limites e restrições, mesmo sendo tal dispositivo tão fundamental para um Estado Democrático de Direito.

A partir da solidificação filosófica citada acima e a consequente aderência de que a liberdade de expressão tem limites, partiu-se em busca de um exemplo que bem elucidasse essa questão: liberdade $\mathrm{X}$ responsabilidade.

Foi encontrado nas manifestações de Chrlottesville o perfeito exemplo, uma vez que presentes todos os requisitos que eram buscados em um evento, para análise (o ódio, a idéia de liberdade irrestrita, o discurso de ódio).

O discurso de ódio foi tão marcante nesse evento que tomou papel central na tese, tornando-se o motivador da restrição a liberdade de 
expressão que os presentes pesquisadores acharam ter os melhores critérios de definição e menos subjetividade.

Dessa maneira, foi constatado que a liberdade de expressão deve ser restringida especificamente nesse caso, não abordando a presente pesquisa sobre outros modos de ofensa, como a injúria racial ou a calúnia, por exemplo.

Ou seja, buscou-se entender o fenômeno pela filosófica já citada e estabeleceu-se que o discurso de ódio é inaceitável, sendo ele, portanto o fator limitador que deve ser tido como o principal para a limitação da liberdade de expressão.

Mais que isso, outro aspecto que se mostrou imprescindível ao longo da pesquisa foi o conflito entre a dignidade da pessoa humana e a liberdade de expressão, ora, foi estabelecido que a liberdade de expressão devia ter limites porque sua responsabilidade não poderia ser ignorada, e que o discurso de ódio deveria ser o principal limitador daquele dispositivo. Acontece que o discurso de ódio fere principalmente o princípio da dignidade humana, u seja, de certo modo, a restrição à liberdade de expressão, nesse sentido, será a própria dignidade da pessoa humana.

Acontece que, para a efetiva limitação da liberdade de expressão, chegou-se à conclusão que a maneira mais eficaz era a penalização via estatal, devido a seu caráter de "enviar uma mensagem" a toda sociedade, de que o discurso de ódio não é tolerável.

Assim, outro conflito se fez presente e tomou a pesquisa, notese, que todos esses "conflitos" possuem por si só uma conotação filosófica muito grande, por isso mencionada a carga filosófica contida nesta pesquisa. Tal conflito foi entra a chamada Autodeterminação e a Heterodeterminação. A autodeterminação se difere da heterodeterminação basicamente no sentido de que a primeira é o indivíduo decidindo o que é melhor para si, enquanto na outra o Estado tomará a frente e decidirá pelos indivíduos como agir.

$\mathrm{Ou}$ seja, na presente pesquisa, concluiu-se que a heterodeterminação era o melhor modo de se propiciar uma segurança à coletividade quanto ao asseguramento do princípio da dignidade da pessoa humana e do direito de não ser ofendido.

Importante ressaltar que esse posicionamento se dá em relação ao discurso de ódio e atribuído especificamente a este tema, não sendo uma ideia geral destes pesquisadores.

Superada essa questão, importante ressaltar a importância, ao contrário de outras pesquisas, não só do material teórico "tradicional", 
como a doutrina, artigos científicos etc, mas de materiais empíricos, como a elucidação dos momentos históricos racistas, da guerra da secessão, além de diversas reportagens e notícias mostrando as manifestações de Charlottesville e discutindo-as, bem como fotografias.

Enfim, cumpre ressaltar o feito da pesquisa realizada em dupla pelos presentes pesquisadores, algo inédito na história da Faculdade de Direito de Franca, que acabou por se tornar modo muito proveitoso, com a correspondente divisão de tarefas e ajuda mútua na realização do projeto, algo que recomendamos imensamente à alunos que tenham medo ou receio de começar um projeto, afinal um amigo sempre torna a jornada mais prazerosa.

\section{REFERÊNCIAS BIBLIOGRÁFICAS}

ALEXY, Robert. Teoria dos direitos fundamentais. São Paulo: Editora Malheiros. $5^{\text {a }}$ ed., 2006, p. 90

BANDEIRA DE MELO, Celso Antônio. Curso de Direito Administrativo. 10ªd. São Paulo: Malheiros 1998,

BARROSO, Luís Roberto, A dignidade da pessoa humana e o direito constitucional contemporâneo, São Paulo: Editora Fórum, 2012

BRASIL. Supremo Tribunal Federal. HC 82.424/RS, Brasília, DF, DJ do dia 19 de março de 2004.

BRUGGER, Winfried. Proibição ou proteção do discurso do ódio? Algumas observações sobre o direito alemão e o americano. Direito Público. Porto Alegre, ano 4 n.15, p.117-136, jan/mar.2007

COMPARATO, Fábio Konder. A afirmação histórica dos direitos humanos.10. ed. São Paulo: Saraiva, 2015.

DA COSTA VENÂNCIO, Fabrício, Umberto Eco está certo: as redes sociais dão direito à palavra a uma legião de imbecis, 2016, http://justificando.cartacapital.com.br/2016/01/28/umberto-eco-estacerto-as-redes-sociais-dao-o-direito-a-palavra-a-uma-legiao-de-imbecis/. Acesso em: 29 de março de 2018

Dicionário do Aurélio. Publicado em: 2016-09-24, revisado em: 2017-02-27. Disponível em: https://dicionariodoaurelio.com/discurso〉. Acesso em: 24 mai. 2019

KARNAL, Leandro. Todos contra todos. Rio de Janeiro: LeYa, 2017

LOPES DE LIMA, Paulo Henrique, os discursos de ódio "hate speech" na jurisprudência do STF, 2014, https://phlopes.jusbrasil.com.br/artigos/142374317/os-discursos-de-odio-hate-speech-najurisprudencia-do-stf. Acesso em: 04 de abril de 2018 
MEYER-PFLUG, Samantha Ribeiro. Liberdade de expressão e discurso de ódio. São Paulo: Editora Revista dos Tribunais, 2009.

NUNES JUNIOR, Flávio Martins Alves, Curso de Direito Constitucional 2ª Edição, São Paulo: Revista dos Tribunais, 2018

PAUL DIAZ, Álvaro, La penalización de la incitación al odio a la luz de la jurisprudencia comparada, Chile, Revista Chilena de Derecho, vol. 38 n 2, 2011

SARLET, Ingo Wolfgang. Dignidade da Pessoa Humana e Direitos Fundamentais na Constituição Federal de 1988.Porto Alegre: Livraria do Advogado, 2001. 